\title{
Madeleine Gagnon, Le vent majeur
}

\section{Simona Rossi}

\section{(Q) OpenEdition}

\section{Journals}

\section{Edizione digitale}

URL: http://journals.openedition.org/studifrancesi/7765

DOI: 10.4000/studifrancesi.7765

ISSN: 2427-5856

\section{Editore}

Rosenberg \& Sellier

\section{Edizione cartacea}

Data di pubblicazione: 1 décembre 2009

Paginazione: 683-684

ISSN: 0039-2944

\section{Notizia bibliografica digitale}

Simona Rossi, «Madeleine Gagnon, Le vent majeur», Studi Francesi [Online], 159 (LIII | III) | 2009, online dal 30 novembre 2015, consultato il 09 janvier 2021. URL: http://journals.openedition.org/ studifrancesi/7765 ; DOI: https://doi.org/10.4000/studifrancesi.7765

Questo documento è stato generato automaticamente il 9 janvier 2021.

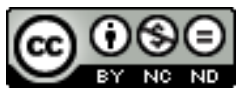

Studi Francesi è distribuita con Licenza Creative Commons Attribuzione - Non commerciale - Non opere derivate 4.0 Internazionale. 


\title{
Madeleine Gagnon, Le vent majeur
}

\author{
Simona Rossi
}

\section{NOTIZIA}

MADELEINE GAGNON, Le vent majeur, Montréal, Typo, 2008, pp. 227.

1 Il romanzo di Madeleine Gagnon è sottotitolato «Journal d'un homme amoureux», un sottotitolo che evidenzia bene quale sarà lo stile dell'opera: intimo, a tratti quasi lirico, caratterizzato da immagini pregnanti, vicine alla pittura e al disegno. Il protagonista, l'uomo Innamorato con la I maiuscola, è Joseph Sully Jacques: egli ama profondamente la madre e il padre, è innamorato persino del sentimento stesso che li unisce. In tenera età, però, Joseph è costretto a subire un grande shock, lo stupro della madre, che lo trasforma in un gelido assassino. Il bambino, infatti, uccide senza remore lo stupratore e questo cambierà per sempre la sua esistenza. Guarirà con grande fatica dalle sue ferite, incapace di accettare le brutture del mondo e il destino talvolta crudele che colpisce l'uomo. Cercherà dunque la delicatezza, la dolcezza, la bellezza, in ogni dove, lasciando fuori dal suo mondo tutto ciò che considera buio e angoscioso. Si viene così a creare una sorta di giardino onirico, all'interno del quale Joseph vive e crea: diventa, infatti, un pittore famoso.

2 Nella mente di Joseph, tuttavia, ci sono troppi fantasmi e di tanto in tanto, quest'uomo docile e solitario, di fronte alle prove della vita, si perde. All'improvviso Joseph non trova più nella pittura tutto l'amore di cui ha bisogno e non è più in grado di dipingere, le sue tele restano bianche. È all'interno di un ospedale psichiatrico che conosce finalmente l'amore della sua vita, Véronique, una pianista che non sa più suonare. I due personaggi si cercano e si trovano, attirandosi come calamite: lui e lei, il pittore e la pianista ai quali la sofferenza del quotidiano ha strappato l'ispirazione, si guariranno a vicenda e insieme torneranno a volare. Un brutto incidente d'auto, però, toglie Véronique a Joseph, che di nuovo precipita nel baratro della disperazione. Ne uscirà più forte, e ancora cadrà, ancora si rialzerà, in un perenne saliscendi che, nel suo essere scontato, si rivela prezioso. Perché è quello della vita. E' un romanzo piacevole, Le vent 
majeur, che conquista per la sua poesia, per il suo quieto navigare nei tumulti dell'esistenza umana. Tra l'altro, grazie allo stile fresco e spontaneo della Gagnon, il lettore entra facilmente in contatto con la spiritualità del protagonista e talvolta, nel corso della lettura, si ha l'impressione d'intuirne i pensieri. Le sensazioni quasi tattili che regala il testo, rivelano la sensibilità dell'autrice, scrittrice, poetessa e pittrice, che da sempre dichiara: «l'espoir naît de trois choses: l'amour, la création d'œuvres, et le désir de connaissance». Un motto che sembra creato apposta per questo romanzo. 